\title{
Re-establishment of efficacy of tofacitinib, an oral JAK inhibitor, after temporary discontinuation in patients with rheumatoid arthritis
}

\author{
Jeffrey Kaine ${ }^{1} \cdot$ John Tesser $^{2} \cdot$ Liza Takiya $^{3} \cdot$ Ryan DeMasi $^{3} \cdot$ Lisy Wang $^{4} \cdot$ Mark Snyder $^{3} \cdot$ Koshika Soma $^{4}$. \\ Haiyun Fan $^{3} \cdot$ Vara Bandi $^{5}$ • Jürgen Wollenhaupt ${ }^{6}$
}

Received: 3 September 2019 / Revised: 17 January 2020 / Accepted: 22 January 2020/Published online: 12 February 2020

(C) The Author(s) 2020

\begin{abstract}
Introduction/objective Tofacitinib is an oral Janus kinase inhibitor for the treatment of rheumatoid arthritis (RA). This post-hoc analysis evaluated the effect of temporary discontinuation and reinitiation of tofacitinib on disease control in patients with RA in the vaccine sub-study of the long-term extension (LTE) study ORAL Sequel (NCT00413699).

Methods The sub-study of ORAL Sequel was a randomized, parallel-group, open-label study. Patients who received tofacitinib $10 \mathrm{mg}$ twice daily for $\geq 3$ months in ORAL Sequel were randomized to receive continuous (tofacitinib monotherapy/with methotrexate) or interrupted (tofacitinib withdrawn for 2 weeks post-randomization then reinitiated as monotherapy/with methotrexate) treatment. Efficacy assessments included ACR20/50/70 response rates, change from baseline $(\Delta)$ in C-reactive protein (CRP), Health Assessment Questionnaire-Disability Index (HAQ-DI), Disease Activity Score in 28 joints, erythrocyte sedimentation rate (DAS28-4 [ESR]), Clinical Disease Activity Index (CDAI), Patient Global Assessment of arthritis (PtGA), Pain (Visual Analog Scale [VAS]), and Physician Global Assessment of arthritis (PGA). Safety was assessed throughout.

Results The sub-study included 99 patients each in the continuous and interrupted treatment groups. ACR20/50 response rates, $\triangle C R P$, $\triangle \mathrm{HAQ}$-DI (day 15), $\triangle \mathrm{DAS} 28-4$ (ESR), $\triangle \mathrm{CDAI}, \triangle \mathrm{PtGA}, \Delta \mathrm{Pain}$ (VAS), and $\triangle \mathrm{PGA}$ were significantly worse in interrupted vs continuous patients during dose interruption, but were generally similar to pre-interruption/continuous treatment levels 28 days postreinitiation. A numerically higher proportion of interrupted patients reported adverse events (49.5\%) vs continuous patients (35.4\%). Conclusions Tofacitinib efficacy can be re-established after temporary withdrawal and reinitiation. The safety profile of patients who temporarily discontinued tofacitinib in the sub-study was consistent with previous tofacitinib LTE studies over 9 years.

Clinical trial registration number NCT00413699
\end{abstract}

Key Points

- In this sub-study of the long-term extension (LTE) study, ORAL Sequel, the efficacy of tofacitinib was re-established after temporary withdrawal

( 2 weeks) and reinitation of treatment in patients with $R A$.

- Patients with RA who temporarily discontinued tofacitinib had similar safety events to those reported in previous LTE studies.

- The results of this sub-study were consistent with a post-hoc analysis of pooled data from two LTE studies, ORAL Sequel and A3921041, which assessed the efficacy of tofacitinib following a treatment discontinuation period of 14-30 days.

Ryan DeMasi was an employee of Pfizer Inc at the time of this analysis

Some data reported in this manuscript have been previously presented at the Annual European Congress of Rheumatology (EULAR), Madrid, Spain, June 14-16, 2017: Kaine J, Tesser J, DeMasi R, Takiya L, Wang L, Snyder M, Fan H, Wollenhaupt J (2017) Reestablishment of efficacy of tofacitinib, an oral Janus kinase inhibitor, in rheumatoid arthritis patients after temporary discontinuation. Ann Rheum Dis. 2017;76(S2):275-276. https://doi.org/10.1136/annrheumdis-2017-eular.2375 and at the American College of Rheumatology (ACR), San Diego, California, USA, November 3-8, 2017: Kaine J, Tesser J, DeMasi R, Takiya L, Wang L, Snyder M, Fan H, Wollenhaupt J (2017) Re-establishment of efficacy of tofacitinib, an oral Janus kinase inhibitor, in rheumatoid arthritis patients after temporary discontinuation. Arthritis Rheum 69 (Suppl 10):523-525. https://acrabstracts.org/abstract/re-establishment-of-efficacy-oftofacitinib-an-oral-janus-kinase-inhibitor-in-rheumatoid-arthritispatients-after-temporary-discontinuation/.
Liza Takiya

Liza.Takiya@pfizer.com

Independent Healthcare Associates Inc, Cullowhee, NC, USA

2 Arizona Arthritis \& Rheumatology Associates, Glendale, AZ, USA

3 Pfizer Inc, Collegeville, PA, USA

Pfizer Inc, Groton, CT, USA

5 Eliassen Group Inc, New London, CT, USA

6 Rheumatology im Struenseehaus, Hamburg, Germany 
Keywords Dose interruption $\cdot$ Efficacy $\cdot$ Rheumatoid arthritis $\cdot$ Safety $\cdot$ Tofacitinib

\section{Introduction}

Rheumatoid arthritis (RA) is an autoimmune disease affecting approximately $0.24 \%$ of the population worldwide [1]. Characterized by systemic inflammation, persistent synovitis and, ultimately, joint destruction [2], it can lead to reduced productivity and impaired health-related quality of life [3].

As a chronic disease, RA requires long-term treatment; however, there may be situations when medication is temporarily discontinued, such as when patients are managing comorbidities (e.g., undergoing surgery or having treatment for infections), drug interactions, or laboratory abnormalities. Previous studies of biologic disease-modifying antirheumatic drugs (bDMARDs) have shown that the temporary discontinuation of treatment was associated with a flare in disease and loss of remission, which was reversed after treatment reinitiation [4-8].

Tofacitinib is an oral Janus kinase inhibitor for the treatment of RA. The efficacy and safety of tofacitinib 5 and $10 \mathrm{mg}$ twice daily (BID) administered as monotherapy or in combination with conventional synthetic (cs)DMARDs, mainly methotrexate (MTX), in patients with moderately to severely active RA, have been demonstrated in Phase 2 [9-13], Phase 3 [14-19], and Phase $3 b / 4$ [20] randomized controlled trials (RCTs) of up to 24-months' duration, and in long-term extension (LTE) studies with up to 114 months of observation [21-23].

The tofacitinib LTE study ORAL Sequel (NCT00413699) $[21,23]$ included a sub-study to assess immune response following the administration of influenza and pneumococcal vaccines in patients with RA receiving tofacitinib, who were randomized to receive a continuous or interrupted tofacitinib treatment regimen [24]. The temporary discontinuation of tofacitinib did not appear to affect the responses to either vaccine [24]. Here, we assess the efficacy and safety of tofacitinib during and after 2 full weeks of temporary discontinuation and reinitiation in patients with RA who participated in the substudy of ORAL Sequel.

\section{Methods}

\section{Study design}

ORAL Sequel (A3921024; NCT00413699) was a global, multicenter, open-label LTE study [21, 23]. Patients were eligible if they were aged $\geq 18$ years, with a diagnosis of RA based on the American College of Rheumatology (ACR) 1987 Revised Criteria, and had participated in a prior Phase 1, 2, or 3 qualifying index study of tofacitinib. The majority of patients who had participated in a Phase 2 qualifying study initiated treatment in
ORAL Sequel with tofacitinib $5 \mathrm{mg}$ BID, whereas the majority of patients who had participated in a Phase 3 qualifying study initiated treatment with tofacitinib $10 \mathrm{mg}$ BID, with the exception of patients from China and Japan who initiated treatment with tofacitinib $5 \mathrm{mg} \mathrm{BID}$ as per the protocol. The tofacitinib dose could be reduced from 10 to $5 \mathrm{mg}$ BID for safety reasons, or increased from 5 to $10 \mathrm{mg}$ BID for reasons of inadequate response. Dose adjustments were at the discretion of the investigator and could be temporary or last the duration of the study. Permitted concomitant RA medications included MTX, leflunomide, sulfasalazine, antimalarials, auranofin, injectable gold preparations, nonsteroidal anti-inflammatory drugs, and glucocorticoids (at approved doses); these were subject to dose adjustments, tapering, and discontinuation at the discretion of the investigator.

Following an amendment to the ORAL Sequel protocol, a sub-study was performed to assess immune response in patients receiving tofacitinib following administration of pneumococcal and influenza vaccines [24]. Patients in this randomized, parallel-group open-label study must have received tofacitinib $10 \mathrm{mg}$ BID for $\geq 3$ months in ORAL Sequel. Those who were receiving MTX must have taken this continuously for $\geq 4$ months, and have been at a stable weekly dose (7.5$25 \mathrm{mg} /$ week) for $\geq 6$ weeks, before randomization. Doses of $<$ $7.5 \mathrm{mg} /$ week were allowed only in cases of intolerance/toxicity, or where higher doses had the possibility to violate the local label. Patients receiving other concomitant RA medications were required to receive stable doses of such medications for $\geq 4$ weeks prior to randomization.

Patients in the sub-study were randomized 1:1 to receive continuous or interrupted treatment (Fig. 1), with stratification by current use of background MTX. The continuous treatment sequence included patients who received tofacitinib $10 \mathrm{mg}$ BID as monotherapy or with MTX. This treatment arm was included to confirm that patients who stopped and restarted treatment had comparable disease activity levels post-reinitiation with those who continued treatment. In the interrupted treatment sequence, tofacitinib $10 \mathrm{mg}$ BID was withdrawn for 2 weeks post-randomization (days 1 to 15), and was subsequently reinitiated as monotherapy or with MTX (as per the original stratification) at day 15 (visit 3). Pneumococcal and influenza vaccines were administered to all patients on day 8 (visit 2). Assessments performed on visit 1 were considered as baseline for the sub-study.

The study was conducted in accordance with the Declaration of Helsinki and the International Conference on Harmonization Good Clinical Practice Guidelines and was approved by the Institutional Review Boards and/or Independent Ethics Committees at each investigational center. All patients provided written informed consent. 


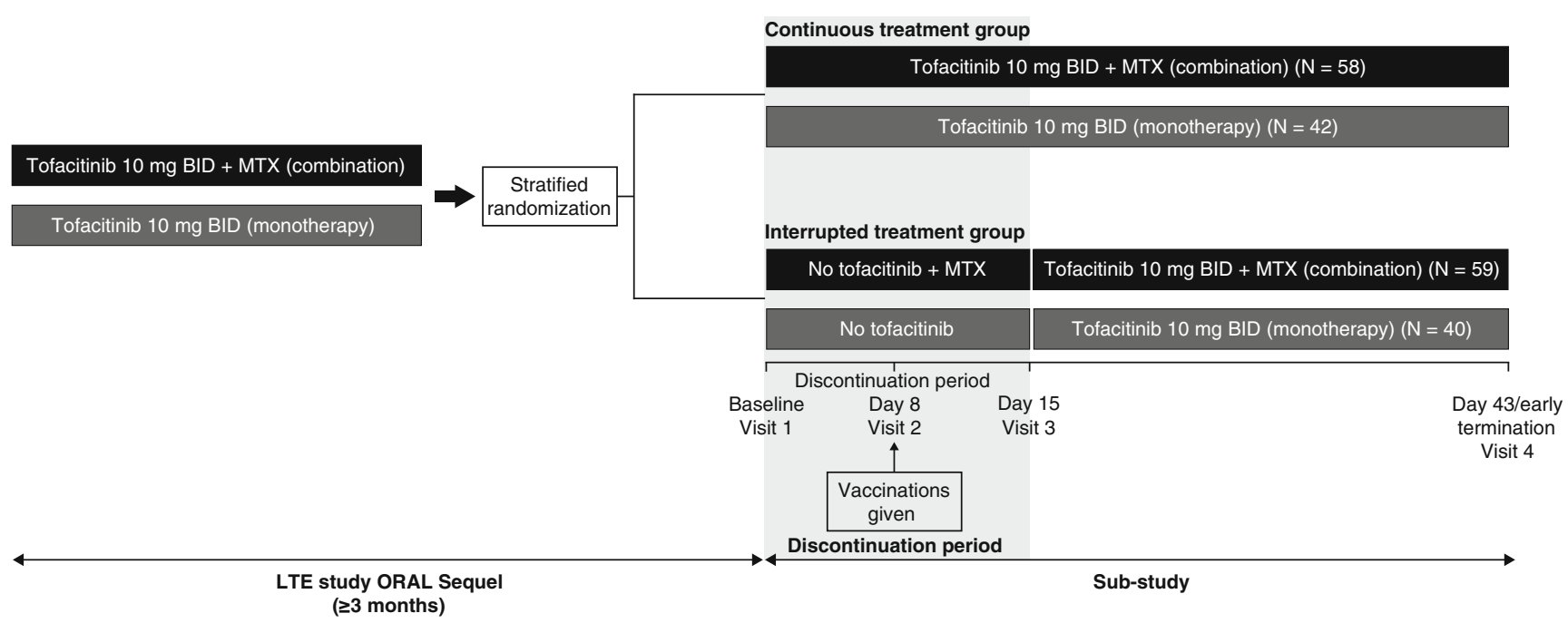

Fig. 1 Schematic of the sub-study of ORAL Sequel. BID twice daily; LTE long-term extension; MTX methotrexate

\section{Outcomes and statistical analyses}

The primary assessment in this post-hoc analysis was the efficacy and safety of tofacitinib after a 2-week temporary discontinuation period followed by treatment reinitiation in patients who participated in the sub-study. Efficacy endpoints were assessed at visit 1 (baseline), visit 2 (day 8; vaccination), visit 3 (day 15; end of withdrawal period; tofacitinib reinitiation for interrupted group), and visit 4 (day 43 [28 days post-reinitiation] or at early termination), and included ACR20, ACR50, and ACR70 response rates, which were defined as $\geq 20 \%, \geq 50 \%$, and $\geq 70 \%$ improvement, respectively, from the baseline of the LTE study, in tender joint count and swollen joint count, and in $\geq 3$ of the other 5 ACR components. The LTE study baseline was the baseline of the index study for patients enrolling into the LTE study $\leq 14$ days from last tofacitinib index study dose, or baseline of ORAL Sequel for patients enrolling into the LTE study $>14$ days from last tofacitinib index study dose. Further outcomes evaluated were changes from the sub-study baseline $(\Delta)$ in C-reactive protein (CRP), Health Assessment Questionnaire-Disability Index (HAQ-DI), Disease Activity Score in 28 joints, erythrocyte sedimentation rate (DAS28-4 [ESR]), Clinical Disease Activity Index (CDAI), Patient Global Assessment of arthritis (PtGA), Pain Visual Analog Scale (VAS) score, and Physician Global Assessment of arthritis (PGA). Safety data were assessed throughout, and included adverse events (AEs), serious AEs (SAEs), and discontinuations due to AEs.

The efficacy analyses included patients who were randomized to the sub-study and were treated with tofacitinib monotherapy or combination therapy. Patients from the continuous treatment group who had received tofacitinib for $\geq 1$ day, and patients from the interrupted treatment group who were withdrawn from tofacitinib for $\geq 1$ day, were considered as having been treated and were included in the efficacy analyses.
A mixed-effects model with repeated measures was used to evaluate the treatment effect for continuous endpoints such as $\triangle \mathrm{CRP}, \triangle \mathrm{HAQ}-\mathrm{DI}, \triangle \mathrm{DAS} 28-4$ (ESR), $\Delta \mathrm{CDAI}, \Delta \mathrm{PtGA}, \Delta \mathrm{Pain}$ (VAS), and $\triangle$ PGA at visits 2, 3, and 4 (days 8, 15, and 43, respectively). This method was selected to maximize the use of all data and thus to increase the validity and efficiency of the model; furthermore, the mixed-effects model can handle missing values if random, as it was assumed to be in most cases. Background MTX use, region, and baseline values were included as covariates, with treatment, visit, and treatment-by-visit interaction as fixed factors. The $95 \%$ confidence interval $(\mathrm{CI})$ of the treatment difference (continuous treatment group-interrupted treatment group), and the $P$ value for the treatment comparison, were calculated within the model. For binary endpoints of ACR response rates, normal approximation for binomial proportions was used to assess the treatment effect. These analyses were exploratory in nature; no multiplicity adjustment was made for comparisons.

The safety analyses included patients who received $\geq 1$ tofacitinib dose or who discontinued tofacitinib during the sub-study of ORAL Sequel.

\section{Results}

\section{Patients}

Overall, 199 patients in the sub-study were randomized to receive study treatment (continuous treatment $N=100$; interrupted treatment $N=99$ ); 198 were treated with tofacitinib for $\geq 1$ day or withdrawn from tofacitinib for $\geq$ 1 day. There were 16 patients with protocol deviations who were not evaluable in the immunogenicity analysis but were included in this post-hoc analysis. Of the 100 patients randomized to continuous treatment, 99 received continuous 
treatment with tofacitinib, and $58(58.6 \%)$ of these patients received concomitant MTX (mean [standard deviation (SD)] baseline dose 14.1 [4.1] mg/week). Of the 99 patients randomized to interrupted treatment, all received interrupted treatment with tofacitinib and $59(59.6 \%)$ received concomitant MTX (mean [SD] baseline dose 15.9 [3.9] mg/week).

Baseline demographics and disease characteristics are presented in Table 1. The continuous and interrupted treatment groups were comparable in terms of age, sex, and race. Baseline values for CRP, HAQ-DI, DAS28-4 (ESR), CDAI, PtGA, Pain (VAS), and PGA appeared generally similar between the continuous and interrupted treatment groups at the start of the sub-study, although CRP values showed a high degree of variability in the interrupted treatment group.

\section{Efficacy assessments}

At the sub-study baseline, the proportion of patients who achieved ACR20 response (95\% CI) was significantly higher in patients receiving continuous tofacitinib treatment $(80.8 \%$ $[71.7,88.0]$ vs interrupted treatment $(67.7 \%$ [57.5, 76.7]; difference $13.1 \%$ [1.1, 25.2]; $p<0.05$ ) (Fig. 2a). The difference between the two groups increased to $28.8 \%(16.0,41.5$; $p<0.0001)$ at day 8 , as although the ACR20 response rate remained fairly constant for patients receiving continuous treatment $(81.4 \%[72.3,88.6])$, it decreased in patients with interrupted treatment $(52.7 \%$ [42.1, 63.1]). By day 43 (28 days after treatment reinitiation), the ACR20 response rate in the interrupted treatment group had increased to $72.6 \%(62.5$, 81.3 ), but was still significantly different from the continuous treatment group $(84.5 \%$ [75.8, 91.1]; difference 11.9 [0.4, 23.4]; $p<0.05)$.

ACR50 response rates $(95 \% \mathrm{CI})$ were similar at sub-study baseline between patients who received continuous $(51.5 \%$ $[41.3,61.7])$ vs interrupted treatment $(46.5 \%$ [36.4, 56.8]; difference $5.1 \%[-8.9,19.0]$ ) (Fig. 2b). The ACR50 response rates remained fairly constant for patients receiving continuous treatment (day $855.7 \%$ [45.2, 65.8]; day $1554.1 \%$ [43.7, 64.2]); day $4354.6 \%$ [44.2, 64.8]); however, the ACR50 responses in the interrupted treatment group decreased slightly and were significantly different from the continuous treatment group at day $8(38.7 \%[28.8,49.4]$; difference $17.0 \%$ [3.0, $31.0] ; p<0.05)$ and day $15(37.1 \%$ [27.5, 47.5]; difference $17.0 \%[3.2,30.7] ; p<0.05$ ). By day 43 (28 days after treatment reinitiation), the ACR50 response rate had increased $(46.3 \%[36.0,56.9])$ and was not significantly different from that of the continuous treatment group (difference $8.3 \%$ [$5.8,22.4])$.
Table 1 Demographics and disease characteristics of patients in the ORAL Sequel sub-study ${ }^{\mathrm{a}}$

\begin{tabular}{lll}
\hline & $\begin{array}{l}\text { Tofacitinib 10 mg BID } \\
\text { Continuous } \\
(N=99)\end{array}$ & $\begin{array}{l}\text { Tofacitinib 10 mg BID } \\
\text { Interrupted } \\
(N=99)\end{array}$ \\
\hline Age (years), mean (SD) & $55.0(11.3)$ & $53.9(9.2)$ \\
Sex, $n$ (\%) & & \\
Male & $15(15.2)$ & $13(13.1)$ \\
Female & $84(84.8)$ & $86(86.9)$ \\
Race, $n(\%)$ & & \\
White & $81(81.8)$ & $83(83.8)$ \\
Black & $3(3.0)$ & $1(1.0)$ \\
Asian & $13(13.1)$ & $14(14.1)$ \\
Other & $2(2.0)$ & $1(1.0)$ \\
BMI (kg/m $\left.{ }^{2}\right)$, mean (SD) & $27.3(6.1)$ & $28.2(6.9)$ \\
CRP (mg/L), mean (SD) & $2.5(3.0)$ & $4.1(10.2)$ \\
HAQ-DI, mean (SD) & $0.9(0.7)$ & $1.0(0.7)$ \\
DAS28-4 (ESR), mean (SD) & $3.6(1.3)$ & $3.7(1.3)$ \\
CDAI, mean (SD) & $10.5(9.5)$ & $11.9(11.6)$ \\
PtGA (mm), mean (SD) & $30.6(21.3)$ & $33.7(22.9)$ \\
Pain (VAS) (mm), mean (SD) & $28.5(22.2)$ & $32.2(23.1)$ \\
PGA (mm), mean (SD) & $16.8(13.2)$ & $18.9(16.3)$ \\
Mean MTX dose (mg/week), mean (SD) & $14.1(4.1)[n=58]$ & $15.9(3.9)[n=59]$ \\
\hline
\end{tabular}

${ }^{\mathrm{a}}$ At the sub-study baseline (prior to interruption). BID twice daily; $B M I$ body mass index; $C D A I$ Clinical Disease Activity Index; $C R P$ C-reactive protein; DAS28-4 (ESR) Disease Activity Score in 28 joints, erythrocyte sedimentation rate; HAQ-DI Health Assessment Questionnaire-Disability Index; MTX methotrexate; $P G A$ Physician Global Assessment of arthritis; PtGA Patient Global Assessment of arthritis; SD standard deviation; VAS visual analog scale 
Fig. 2 a ACR20 response rates, b ACR50 response rates, and c ACR70 response rates over time during the sub-study of ORAL Sequel. $* p<0.05 ; * * p<0.001$; $* * * p<0.0001$ for interrupted vs continuous treatment. Shaded area indicates the dose interruption period. ${ }^{\mathrm{a}}$ The ACR response rate at each visit is the proportion of patients achieving improvement from the baseline of the index study for patients enrolling into the LTE study $\leq 14$ days from last tofacitinib dose in the index study or baseline of ORAL Sequel for patients enrolling into the LTE study $>14$ days from last tofacitinib dose in the index study ${ }^{b} \mathrm{ACR}$ response rate of continuous treatment group - response rate of interrupted treatment group ${ }^{\mathrm{c}}$ Baseline visit of sub-study. ACR American College of Rheumatology; BID twice daily; $C I$ confidence interval; LTE longterm extension a

- Tofacitinib $10 \mathrm{mg}$ BID 'continuous'

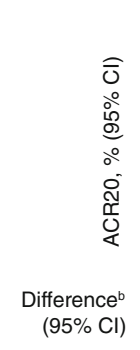

b

b

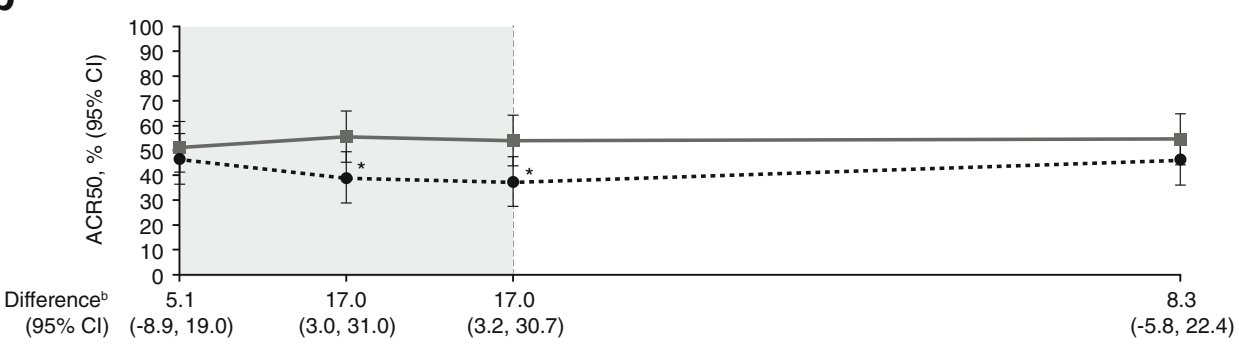

C

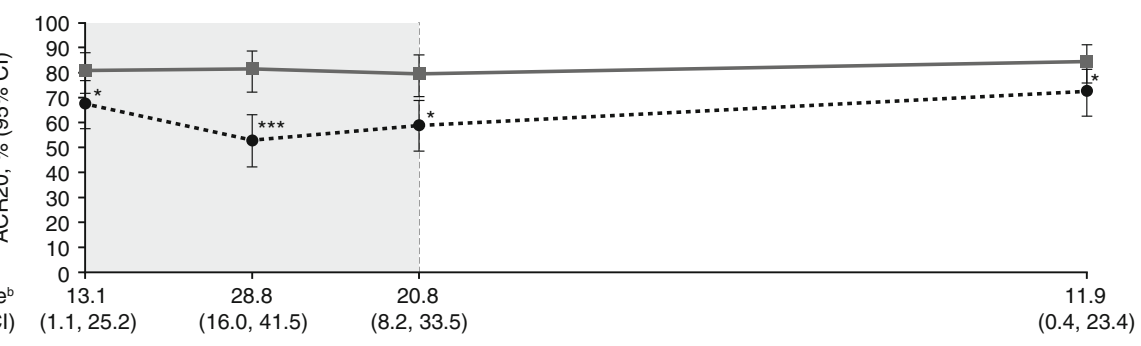

..•.. Tofacitinib $10 \mathrm{mg}$ BID 'interrupted'

ACR20

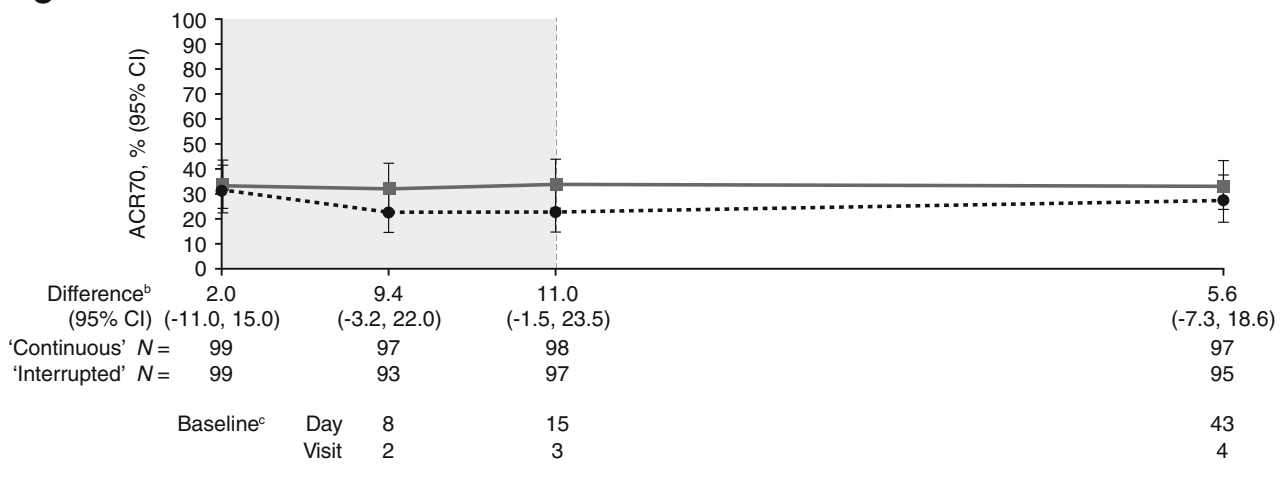

ACR70 response rates (95\% CI) in the continuous treatment group remained constant throughout the study (sub-study baseline 33.3\% [24.2, 43.5]; day $832.0 \%$ [22.9, 42.2]; day $1533.7 \%$ [24.4, 43.9]; day $4333.0 \%$ $[23.8,43.3]$ ) (Fig. 2c). ACR70 response rates in the interrupted treatment group were numerically lower but were not significantly different from the continuous treatment group throughout the study (sub-study baseline $31.3 \%[22.4,41.4]$; day $822.6 \%[14.6,32.4]$; day 15 $22.7 \%$ [14.8, 32.3]; day $4327.4 \%[18.7,37.5])$.

The increases from baseline in CRP, HAQ-DI, DAS28-4 (ESR), and CDAI were generally significantly greater during treatment interruption vs the continuous treatment group; however, at day 43 , changes from baseline in these outcomes were similar to the sub-study baseline level, and there was little change vs the continuous treatment group (Fig. 3). The continuous treatment group showed minimal changes from baseline in these outcomes up to day 43. Unlike CRP, DAS28-4 (ESR), and CDAI, differences in the increases from baseline in
HAQ-DI in the two treatment groups were very close at day 8 (1 week post-treatment withdrawal), although they were significantly different at day 15 ( 2 weeks post-treatment withdrawal) (Fig. 3). Similar trends were also observed in $\triangle \mathrm{PtGA}, \triangle \mathrm{Pain}$ (VAS), and $\triangle \mathrm{PGA}$, with significant differences between the two groups observed during days 8 and 15 (Fig. 4). At day 43, values were similar to the sub-study baseline level, although the difference between treatments for $\triangle \mathrm{PtGA}$ was still significant, likely due to the decrease in PtGA observed in the continuous treatment group throughout the sub-study.

\section{Safety assessments}

Overall, a numerically higher proportion of patients reporting AEs (all causality and treatment-related) were observed in the interrupted vs continuous treatment group of the sub-study (Table 2). The most frequent treatment-emergent AEs (all causality) by Medical Dictionary for Regulatory Activities (MedDRA) preferred term across both treatment groups were bronchitis and 
Fig. 3 LSM changes from baseline in a CRP levels, b HAQ-DI, c DAS28-4 (ESR), and $\mathbf{d}$ CDAI over time during the sub-study of ORAL Sequel. ${ }^{*} p<0.05 ; * * p<0.001$; *** $p<0.0001$ for interrupted vs continuous treatment. Shaded area indicates the dose interruption period. Baseline was defined as Visit 1 of the sub-study. ${ }^{\mathrm{a}} \mathrm{LSM} \Delta$ of continuous treatment group - LSM $\Delta$ of interrupted treatment group. $\Delta$ change from baseline; BID twice daily; $C D A I$ Clinical Disease Activity Index; $C I$ confidence interval; $C R P \mathrm{C}$ reactive protein; DAS28-4 (ESR) Disease Activity Score in 28 joints, erythrocyte sedimentation rate; $H A Q-D I$ Health Assessment Questionnaire-Disability Index; $L S M$ least squares mean; $S E$ standard error a

$\rightarrow$ Tofacitinib $10 \mathrm{mg}$ BID 'continuous' $\quad$.-.. Tofacitinib $10 \mathrm{mg}$ BID 'interrupted'

CRP

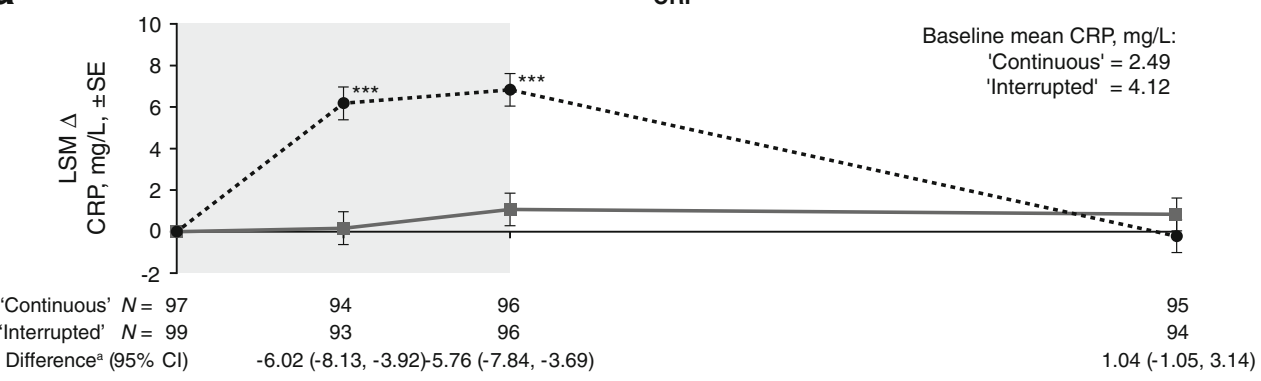

b

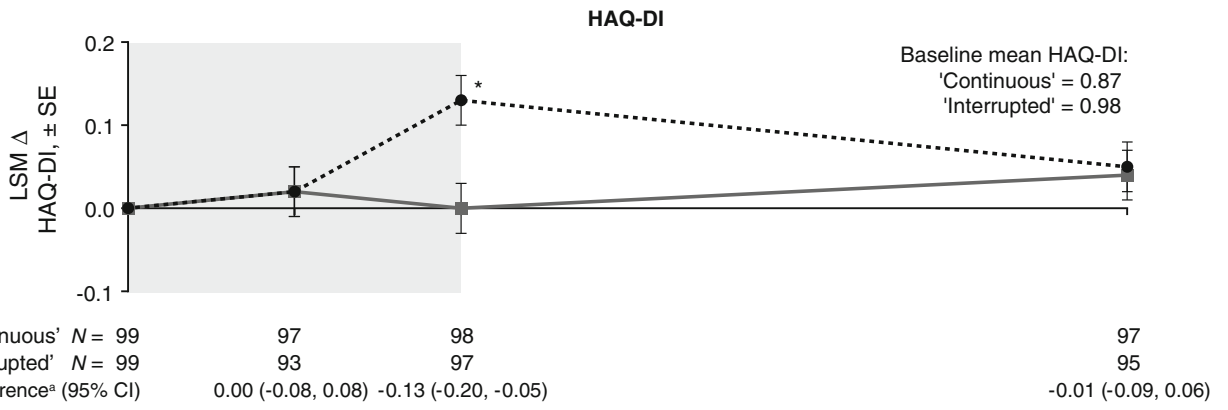

C

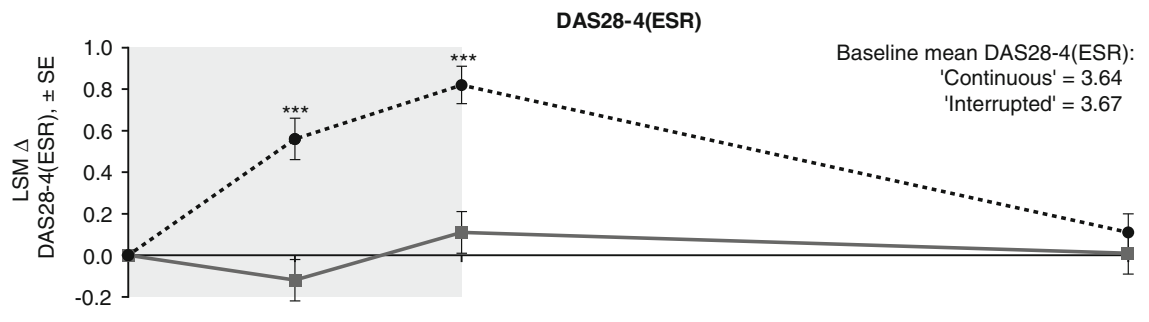

'Continuous' $N=95$ 'Interrupted' $N=97$

Difference $^{\mathrm{a}}(95 \% \mathrm{Cl})$

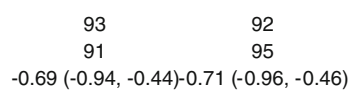

93
93

$-0.10(-0.34,0.15)$

d

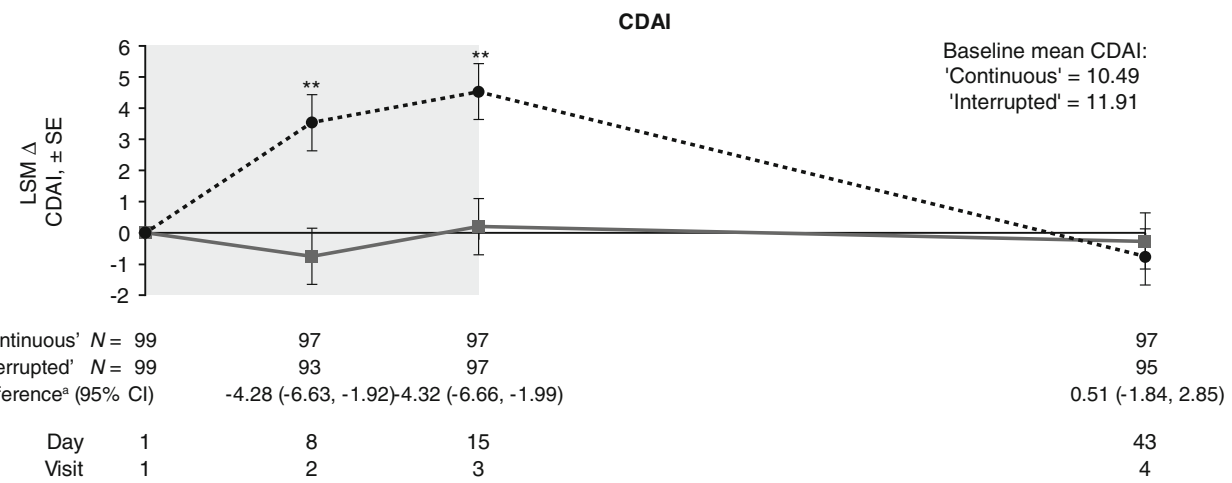

upper respiratory tract infection, followed by vaccination-related immunization reaction, myalgia, and rash (Table 2).

SAEs occurred in 3 patients in each treatment group; these were cataract, squamous cell carcinoma of the skin, and pharyngeal hemorrhage in the continuous treatment group; and colitis, atrial flutter, and lymph node tuberculosis (considered by the investigator to be treatment-related) in the interrupted treatment group.
Two patients in the interrupted treatment group discontinued treatment due to AEs of colitis and lymph node tuberculosis. One patient in the interrupted treatment group reported an AE of "aggravation of rheumatoid arthritis"; however, this patient did not permanently discontinue treatment due to the $\mathrm{AE}$, and no patients withdrew from the study due to disease flare. 
a

$$
\text { 过京市 }
$$

'Continuous' $N=99$ 'Interrupted' $N=99$ Difference $^{\mathrm{a}}(95 \% \mathrm{Cl})$

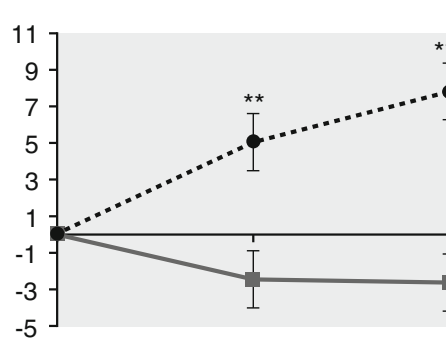

$\begin{array}{cc}97 & 97 \\ 93 & 97 \\ -7.51(-11.57,-3.45) & -10.42(-14.45,-6.39)\end{array}$
PtGA

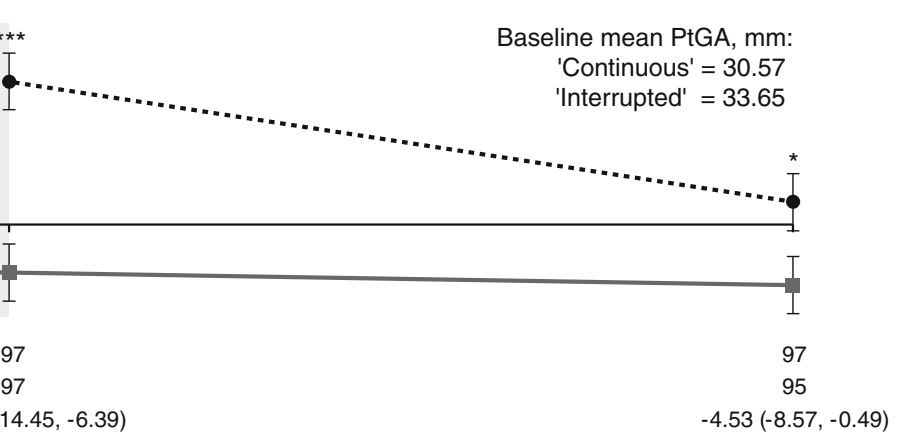

b

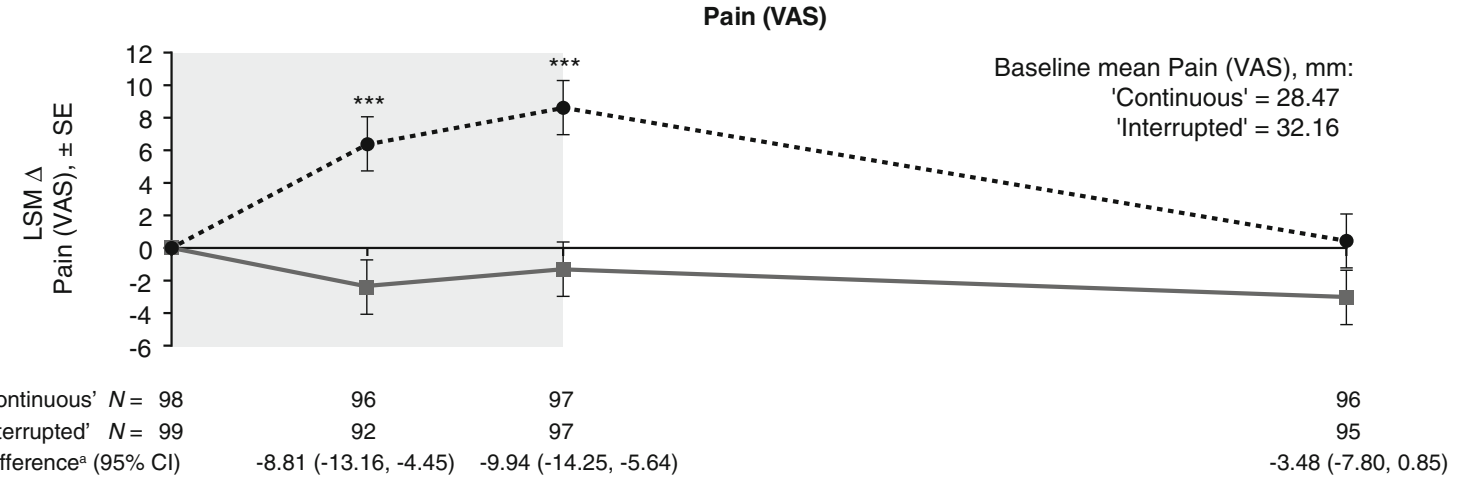

c

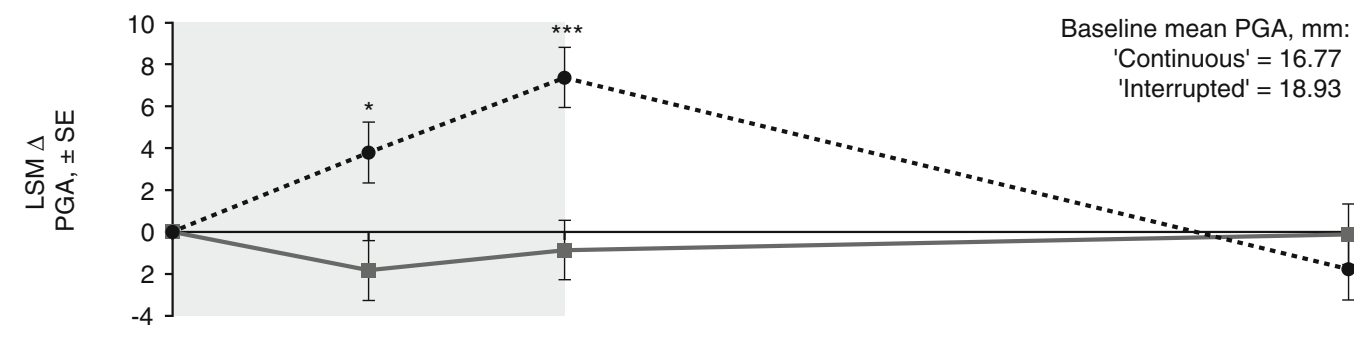

'Continuous' $N=99$ 'Interrupted' $N=99$ Difference $^{\mathrm{a}}(95 \% \mathrm{Cl})$

$$
\begin{array}{cc}
97 & 98 \\
93 & 97 \\
-5.63(-9.39,-1.86) & -8.23(-11.96,-4.50) \\
8 & 15 \\
2 & 3
\end{array}
$$

Fig. 4 LSM changes from baseline in a PtGA, b Pain (VAS), and $\mathbf{c}$ PGA over time during the sub-study of ORAL Sequel. $* p<0.05 ; * p<0.001$; $* * * p<0.0001$ for interrupted vs continuous treatment. Shaded area indicates the dose interruption period. Baseline was defined as Visit 1 of the sub-study. ${ }^{\text {a LSM }} \Delta$ of continuous treatment group - LSM $\Delta$ of

\section{Discussion}

In this analysis, patients who participated in the sub-study of the LTE study ORAL Sequel showed increased disease activity during treatment interruption. Indeed, the $\triangle \mathrm{DAS} 28-4$ (ESR) in the interrupted treatment group was $>0.6$ (the measurement error) [25] at day 15, indicating a relevant increase in DAS28-4 (ESR) when tofacitinib was interrupted. ACR20/50 response rates, $\triangle \mathrm{CRP}$ levels, $\triangle \mathrm{HAQ}$-DI, $\triangle \mathrm{CDAI}, \triangle \mathrm{PtGA}$,

PGA 
Table 2 Treatment-emergent AEs during the sub-study of ORAL Sequel

\begin{tabular}{|c|c|c|c|c|}
\hline & \multicolumn{2}{|l|}{ All causalities } & \multicolumn{2}{|l|}{ Treatment-related } \\
\hline & $\begin{array}{l}\text { Tofacitinib } 10 \mathrm{mg} \text { BID } \\
\text { Continuous } \\
(N=99)\end{array}$ & $\begin{array}{l}\text { Tofacitinib } 10 \mathrm{mg} \text { BID } \\
\text { Interrupted } \\
(N=99)\end{array}$ & $\begin{array}{l}\text { Tofacitinib } 10 \mathrm{mg} \text { BID } \\
\text { Continuous } \\
(N=99)\end{array}$ & $\begin{array}{l}\text { Tofacitinib } 10 \mathrm{mg} \text { BID } \\
\text { Interrupted } \\
(N=99)\end{array}$ \\
\hline Number of AEs & 50 & 95 & 5 & 14 \\
\hline Patients with AEs, $n(\%)$ & $35(35.4)$ & $49(49.5)$ & $4(4.0)$ & $13(13.1)$ \\
\hline Patients with SAEs, $n(\%)$ & $3(3.0)$ & $3(3.0)$ & 0 & $1(1.0)$ \\
\hline Patients with AEs leading to discontinuation, $n(\%)$ & 0 & $2(2.0)$ & 0 & $1(1.0)$ \\
\hline \multicolumn{5}{|l|}{ Most frequent ${ }^{\mathrm{a}} \mathrm{AEs}$ by preferred term, $n(\%)$} \\
\hline Immunization reaction & $1(1.0)$ & $4(4.0)$ & 0 & 0 \\
\hline Bronchitis & $2(2.0)$ & $4(4.0)$ & 0 & $1(1.0)$ \\
\hline Upper respiratory tract infection & $3(3.0)$ & $3(3.0)$ & $1(1.0)$ & 0 \\
\hline Myalgia & $1(1.0)$ & $4(4.0)$ & $1(1.0)$ & 0 \\
\hline Rash & 0 & $5(5.1)$ & 0 & $1(1.0)$ \\
\hline
\end{tabular}

${ }^{\text {a }}$ Occurring in $\geq 5 \%$ of patients (all causalities) across both treatment groups. $A E$ adverse event; $B I D$ twice daily; $S A E$ serious adverse event

level of improvement within the same timeframe. However, within 1 month of treatment reinitiation, all efficacy outcomes, except for ACR20 response rate and $\triangle \mathrm{PtGA}$, were similar to those before discontinuation. Compared with patients who received continuous treatment, there were also no significant changes in efficacy outcomes (with the exception of ACR20 response rate and $\triangle \mathrm{PtGA}$ ) within 1 month of treatment reinitiation for patients with treatment interruption. It should be noted that ACR20 response rates at the LTE study baseline were significantly higher in patients in the continuous vs interrupted treatment group, which may have skewed the response rates throughout the study; however, other efficacy outcomes, which were measured at the sub-study baseline, were generally similar between the two groups. A numerically higher proportion of patients experienced AEs in the interrupted vs continuous treatment group. The profile of AEs and SAEs, in terms of events reported, was similar to those reported previously in the LTE studies over 9 years $[21,23]$.

The results of the sub-study were in line with a posthoc analysis of pooled data from two LTE studies, ORAL Sequel and A3921041, which was performed to confirm the findings from the sub-study and to further assess the efficacy of tofacitinib following a treatment discontinuation period of 14-30 days, which may better reflect real-world circumstances [27]. Similar efficacy responses were observed at pre- and post-interruption visits, suggesting that there was no loss of efficacy after reinitiation of tofacitinib following temporary discontinuation.

Previous studies of other RA therapies have also shown worsening of disease activity upon treatment discontinuation, followed by subsequent regaining of disease control after treatment reinitiation, although these have been assessed over a longer time period. A review of MTX and bDMARDs in non-randomized trials as well as RCTs reported that $35-87 \%$ of patients with RA relapsed 1 year after discontinuing treatment in RCTs, with remission and low disease activity (LDA) generally re-established by reinitiation of the previous treatment [28]. In a previous study of patients who had achieved remission or LDA with tumor necrosis factor inhibitors (TNFi) and who had subsequently discontinued treatment, flares were reported in $40.1 \%$ and $51.2 \%$ of patients within 6 and 12 months, respectively [8]; studies of specific TNFi have shown rates of flares to be $28.4 \%$ within 1 year (mean duration 6.4 months) for infliximab and $87.0 \%$ within 48 weeks (median time to relapse 6 weeks) for etanercept $[4,5]$. Most patients who restarted TNFi treatment after a flare regained disease control $[4,5,8]$. Similarly, a non-randomized study of various TNFi, including adalimumab, etanercept, and infliximab, found that out of 20 patients evaluated, who had achieved remission, 8 (40\%) relapsed within 3 months, and 15 (75\%) relapsed within 12 months of discontinuing treatment (mean time to relapse 14.7 weeks). All regained remission after reinitiating the same treatment [6]. A Phase 3 RCT, ACT-RAY, has also shown that the discontinuation of tocilizumab in patients with sustained remission resulted in the relapse of $84.0 \%$ of patients, with $82.5 \%$ (tocilizumab with MTX) or $88.5 \%$ (tocilizumab with placebo) experiencing flares within 52 weeks. Rapid improvements in disease activity (measured by DAS28-[ESR]) were observed after tocilizumab reinitiation [7]. Additionally, in the Phase $3 \mathrm{~b}$ ALLOW study, patients experienced a small increase in disease activity (measured by DAS28-[CRP]) and slight worsening of physical function (measured by HAQ-DI) upon withdrawal of subcutaneous abatacept for 12 weeks; these showed improvement within 1 month of treatment reinitiation [29].

In this sub-study, patients did have a significant increase in disease activity after discontinuing tofacitinib. These patients appeared to experience flares sooner (within 2 weeks) vs the 
bDMARDs in the aforementioned studies [4-7]. This may be a function of the half-life of the drugs, as tofacitinib immediate-release formulation has a relatively short half-life $(\sim 3 \mathrm{~h}$ ) [30] and must be dosed more frequently (BID) than the commonly used bDMARDs (anakinra has a half-life of 4-6 h and is dosed daily; several bDMARDs, including the TNFi, have half-lives ranging from 4 to $\sim 14$ days [31]).

The sub-study showed that the temporary withdrawal of tofacitinib leads to significant worsening of disease control, but that disease control is regained after treatment reinitiation, suggesting that tofacitinib is an appropriate treatment to be reinitiated following disease activity flares during treatment interruption. Nevertheless, several limitations must be considered when interpreting these results. The sub-study was the only study in the tofacitinib clinical trial program where there was a mandated, randomized, and systematically monitored temporary discontinuation and reinitiation of tofacitinib; however, it was not designed to evaluate the withdrawal effect of tofacitinib. The sample size was also limited by the study design. Moreover, following treatment reinitiation, the follow-up period was relatively short (28 days). As such, further studies with more participants and a longer follow-up period may provide valuable insights into whether there are any long-term impacts of temporary tofacitinib withdrawal. Furthermore, the dose of tofacitinib used was $10 \mathrm{mg}$ BID; however, the approved dose in most countries for the treatment of moderately to severely active RA is $5 \mathrm{mg}$ BID. Additionally, all patients in the sub-study received vaccinations at day 8 , which may have affected both the treatment response and the occurrence of AEs. A final limitation is that the patients in this analysis were part of the ORAL Sequel study population, and therefore had previously tolerated and responded to tofacitinib in the index studies.

In summary, the results of this analysis showed that disease outcomes worsened during the temporary discontinuation of tofacitinib, and that the efficacy of tofacitinib can be reestablished after the temporary withdrawal and reinitiation of the drug. The profiles of treatment-emergent AEs were consistent with AEs previously reported with long-term tofacitinib treatment [21, 23].

Acknowledgments Medical writing support, under the guidance of the authors, was provided by Christina Viegelmann, PhD, CMC Connect, McCann Health Medical Communications, and was funded by Pfizer Inc, New York, NY, USA in accordance with Good Publication Practice (GPP3) guidelines (Ann Intern Med 2015; 163:461-464).

Data sharing Upon request, and subject to certain criteria, conditions, and exceptions (see https://www.pfizer.com/science/clinical-trials/trialdata-and-results for more information), Pfizer will provide access to individual de-identified participant data from Pfizer-sponsored global interventional clinical studies conducted for medicines, vaccines, and medical devices (1) for indications that have been approved in the US and/or EU or (2) in programs that have been terminated (i.e., development for all indications has been discontinued). Pfizer will also consider requests for the protocol, data dictionary, and statistical analysis plan. Data may be requested from Pfizer trials 24 months after study completion. The deidentified participant data will be made available to researchers whose proposals meet the research criteria and other conditions, and for which an exception does not apply, via a secure portal. To gain access, data requestors must enter into a data access agreement with Pfizer.

Authors' contributions All authors meet the ICJME guidelines for authorship and contributed equally to the design of the project, the discussion of the results, and the preparation of the manuscript. All authors read and approved the final version of the manuscript.

Funding These studies were sponsored by Pfizer Inc.

Compliance with ethical standards The study was conducted in accordance with the Declaration of Helsinki and the International Conference on Harmonization Good Clinical Practice Guidelines and was approved by the Institutional Review Boards and/or Independent Ethics Committees at each investigational center.

Conflict of interest $\mathrm{J}$ Kaine and $\mathrm{J}$ Tesser have received grant/research support from, are consultants for, and are on the speaker's bureau for, Pfizer Inc. R DeMasi was an employee and shareholder of Pfizer Inc. at the time of the analysis. L Takiya, L Wang, M Snyder, K Soma, and H Fan are employees and shareholders of Pfizer Inc. V Bandi is a consultant for Pfizer Inc. through the Eliassen Group Inc. J Wollenhaupt is a consultant for, and is on the speaker's bureau for, Pfizer Inc.

Informed consent Informed consent was obtained from all individual participants included in the study.

Open Access This article is licensed under a Creative Commons Attribution 4.0 International License, which permits use, sharing, adaptation, distribution and reproduction in any medium or format, as long as you give appropriate credit to the original author(s) and the source, provide a link to the Creative Commons licence, and indicate if changes were made. The images or other third party material in this article are included in the article's Creative Commons licence, unless indicated otherwise in a credit line to the material. If material is not included in the article's Creative Commons licence and your intended use is not permitted by statutory regulation or exceeds the permitted use, you will need to obtain permission directly from the copyright holder. To view a copy of this licence, visit http://creativecommons.org/licenses/by/4.0/.

\section{References}

1. Cross M, Smith E, Hoy D, Carmona L, Wolfe F, Vos T, Williams B, Gabriel S, Lassere M, Johns N, Buchbinder R, Woolf A, March L (2014) The global burden of rheumatoid arthritis: estimates from the global burden of disease 2010 study. Ann Rheum Dis 73:13161322. https://doi.org/10.1136/annrheumdis-2013-204627

2. Scott DL, Wolfe F, Huizinga TW (2010) Rheumatoid arthritis. Lancet 376:1094-1108. https://doi.org/10.1016/S0140-6736(10)60826-4

3. Strand V, Khanna D (2010) The impact of rheumatoid arthritis and treatment on patients' lives. Clin Exp Rheumatol 28:S32-S40

4. van Vollenhoven RF, Østergaard M, Leirisalo-Repo M, Uhlig T, Jansson M, Larsson E, Brock F, Franck-Larsson K (2016) Full dose, reduced dose or discontinuation of etanercept in rheumatoid arthritis. Ann Rheum Dis 75:52-58. https://doi.org/10.1136/annrheumdis-2014205726 
5. Tanaka Y, Takeuchi T, Mimori T, Saito K, Nawata M, Kameda H, Nojima T, Miyasaka N, Koike T, investigators RRRs (2010) Discontinuation of infliximab after attaining low disease activity in patients with rheumatoid arthritis: RRR (remission induction by Remicade in RA) study. Ann Rheum Dis 69:1286-1291. https:// doi.org/10.1136/ard.2009.121491

6. Brocq O, Millasseau E, Albert C, Grisot C, Flory P, Roux CH, Euller-Ziegler L (2009) Effect of discontinuing TNFalpha antagonist therapy in patients with remission of rheumatoid arthritis. Joint Bone Spine 76:350-355. https://doi.org/10.1016/j.jbspin.2008.11. 009

7. Huizinga TW, Conaghan PG, Martin-Mola E, Schett G, Amital H, Xavier RM, Troum O, Aassi M, Bernasconi C, Dougados M (2015) Clinical and radiographic outcomes at 2 years and the effect of tocilizumab discontinuation following sustained remission in the second and third year of the ACT-RAY study. Ann Rheum Dis 74:35-43. https://doi.org/10.1136/annrheumdis-2014-205752

8. Ghiti Moghadam M, Vonkeman HE, Ten Klooster PM, Tekstra J, van Schaardenburg D, Starmans-Kool M, Brouwer E, Bos R, Lems WF, Colin EM, Allaart CF, Meek IL, Landewe R, Bernelot Moens HJ, van Riel PL, van de Laar MA, Jansen TL, Dutch National PC (2016) Stopping tumor necrosis factor inhibitor treatment in patients with established rheumatoid arthritis in remission or with stable low disease activity: a pragmatic multicenter, open-label randomized controlled trial. Arthritis Rheumatol 68:1810-1817. https://doi.org/10.1002/art.39626

9. Fleischmann R, Cutolo M, Genovese MC, Lee EB, Kanik KS, Sadis S, Connell CA, Gruben D, Krishnaswami S, Wallenstein G, Wilkinson BE, Zwillich SH (2012) Phase IIb dose-ranging study of the oral JAK inhibitor tofacitinib (CP-690,550) or adalimumab monotherapy versus placebo in patients with active rheumatoid arthritis with an inadequate response to disease-modifying antirheumatic drugs. Arthritis Rheum 64:617-629. https://doi.org/10.1002/art.33383

10. Kremer JM, Cohen S, Wilkinson BE, Connell CA, French JL, Gomez-Reino J, Gruben D, Kanik KS, Krishnaswami S, PascualRamos V, Wallenstein G, Zwillich SH (2012) A phase IIb doseranging study of the oral JAK inhibitor tofacitinib (CP-690,550) versus placebo in combination with background methotrexate in patients with active rheumatoid arthritis and an inadequate response to methotrexate alone. Arthritis Rheum 64:970-981. https://doi. org/10.1002/art.33419

11. Kremer JM, Bloom BJ, Breedveld FC, Coombs JH, Fletcher MP, Gruben D, Krishnaswami S, Burgos-Vargas R, Wilkinson B, Zerbini CAF, Zwillich SH (2009) The safety and efficacy of a JAK inhibitor in patients with active rheumatoid arthritis: results of a double-blind, placebo-controlled phase IIa trial of three dosage levels of CP-690,550 versus placebo. Arthritis Rheum 60:18951905. https://doi.org/10.1002/art.24567

12. Tanaka Y, Takeuchi T, Yamanaka H, Nakamura H, Toyoizumi S, Zwillich S (2015) Efficacy and safety of tofacitinib as monotherapy in Japanese patients with active rheumatoid arthritis: a 12-week, randomized, phase 2 study. Mod Rheumatol 25:514-521. https:// doi.org/10.3109/14397595.2014.995875

13. Tanaka Y, Suzuki M, Nakamura H, Toyoizumi S, Zwillich SH, Tofacitinib Study Investigators (2011) Phase II study of tofacitinib (CP-690,550) combined with methotrexate in patients with rheumatoid arthritis and an inadequate response to methotrexate. Arthritis Care Res (Hoboken) 63:1150-1158. https://doi.org/10. 1002/acr.20494

14. Burmester GR, Blanco R, Charles-Schoeman C, Wollenhaupt J, Zerbini C, Benda B, Gruben D, Wallenstein G, Krishnaswami S, Zwillich SH, Koncz T, Soma K, Bradley J, Mebus C, on behalf of the ORAL Step Investigators (2013) Tofacitinib (CP-690,550) in combination with methotrexate in patients with active rheumatoid arthritis with an inadequate response to tumour necrosis factor inhibitors: a randomised phase 3 trial. Lancet 381:451-460. https://doi.org/10.1016/S0140-6736(12)61424-X

15. Fleischmann R, Kremer J, Cush J, Schulze-Koops H, Connell CA, Bradley JD, Gruben D, Wallenstein GV, Zwillich SH, Kanik KS, for the ORAL Solo Investigators (2012) Placebo-controlled trial of tofacitinib monotherapy in rheumatoid arthritis. N Engl J Med 367: 495-507. https://doi.org/10.1056/NEJMoa1109071

16. Kremer J, Li Z-G, Hall S, Fleischmann R, Genovese M, MartinMola E, Isaacs JD, Gruben D, Wallenstein G, Krishnaswami S, Zwillich SH, Koncz T, Riese R, Bradley J (2013) Tofacitinib in combination with nonbiologic disease-modifying antirheumatic drugs in patients with active rheumatoid arthritis: a randomized trial. Ann Intern Med 159:253-261. https://doi.org/10.7326/00034819-159-4-201308200-00006

17. Lee EB, Fleischmann R, Hall S, Wilkinson B, Bradley J, Gruben D, Koncz T, Krishnaswami S, Wallenstein GV, Zang C, Zwillich SH, van Vollenhoven RF, for the ORAL Start Investigators (2014) Tofacitinib versus methotrexate in rheumatoid arthritis. N Engl J Med 370:2377-2386. https://doi.org/10.1056/NEJMoa1310476

18. van der Heijde D, Tanaka Y, Fleischmann R, Keystone E, Kremer J, Zerbini C, Cardiel MH, Cohen S, Nash P, Song YW, Tegzová D, Wyman BT, Gruben D, Benda B, Wallenstein G, Krishnaswami S, Zwillich SH, Bradley JD, Connell CA, and the ORAL Scan Investigators (2013) Tofacitinib (CP-690,550) in patients with rheumatoid arthritis receiving methotrexate: twelve-month data from a twenty-four-month phase III randomized radiographic study. Arthritis Rheum 65:559-570. https://doi.org/10.1002/art.37816

19. van Vollenhoven RF, Fleischmann R, Cohen S, Lee EB, García Meijide JA, Wagner S, Forejtova S, Zwillich SH, Gruben D, Koncz T, Wallenstein GV, Krishnaswami S, Bradley JD, Wilkinson B, for the ORAL Standard Investigators (2012) Tofacitinib or adalimumab versus placebo in rheumatoid arthritis. N Engl J Med 367:508-519. https://doi.org/10.1056/ NEJMoa1112072

20. Fleischmann R, Mysler E, Hall S, Kivitz AJ, Moots RJ, Luo Z, DeMasi R, Soma K, Zhang R, Takiya L, Tatulych S, Mojcik C, Krishnaswami S, Menon S, Smolen JS, on behalf of the ORAL Strategy investigators (2017) Efficacy and safety of tofacitinib monotherapy, tofacitinib with methotrexate, and adalimumab with methotrexate in patients with rheumatoid arthritis (ORAL Strategy): a phase $3 \mathrm{~b} / 4$, double-blind, head-to-head, randomised controlled trial. Lancet 390:457-468. https://doi.org/10.1016/ S0140-6736(17)31618-5

21. Wollenhaupt J, Silverfield J, Lee EB, Curtis JR, Wood SP, Soma K, Nduaka CI, Benda B, Gruben D, Nakamura H, Komuro Y, Zwillich SH, Wang L, Riese RJ (2014) Safety and efficacy of tofacitinib, an oral Janus kinase inhibitor, for the treatment of rheumatoid arthritis in open-label, longterm extension studies. J Rheumatol 41:837-852. https://doi.org/10.3899/jrheum.130683

22. Yamanaka H, Tanaka Y, Takeuchi T, Sugiyama N, Yuasa H, Toyoizumi S, Morishima Y, Hirose T, Zwillich S (2016) Tofacitinib, an oral Janus kinase inhibitor, as monotherapy or with background methotrexate, in Japanese patients with rheumatoid arthritis: an open-label, long-term extension study. Arthritis Res Ther 18:34. https://doi.org/10.1186/s13075-016-0932-2

23. Wollenhaupt J, Lee EB, Curtis JR, Silverfield J, Terry K, Soma K, Mojcik C, DeMasi R, Strengholt S, Kwok K, Lazariciu I, Wang L, Cohen S (2019) Safety and efficacy of tofacitinib for up to 9.5 years in the treatment of rheumatoid arthritis: final results of a global, open-label, long-term extension study. Arthritis Res Ther 21:89. https://doi.org/10.1186/s13075-019-1866-2

24. Winthrop KL, Silverfield J, Racewicz A, Neal J, Lee EB, Hrycaj P, Gomez-Reino J, Soma K, Mebus C, Wilkinson B, Hodge J, Fan H, Wang T, Bingham CO 3rd (2016) The effect of tofacitinib on pneumococcal and influenza vaccine 
responses in rheumatoid arthritis. Ann Rheum Dis 75:687695. https://doi.org/10.1136/annrheumdis-2014-207191

25. van Gestel AM, Prevoo ML, van 't Hof MA, van Rijswijk MH, van de Putte LB, van Riel PL (1996) Development and validation of the European League Against Rheumatism response criteria for rheumatoid arthritis. Comparison with the preliminary American College of Rheumatology and the World Health Organization/ International League Against Rheumatism Criteria. Arthritis Rheum 39:34-40

26. Fleischmann R, Strand V, Wilkinson B, Kwok K, Bananis E (2016) Relationship between clinical and patient-reported outcomes in a phase 3 trial of tofacitinib or MTX in MTX-naïve patients with rheumatoid arthritis. RMD Open 2:e000232. https://doi.org/10. 1136/rmdopen-2015-000232

27. Kaine J, Tesser J, DeMasi R, Takiya L, Wang L, Snyder M, Fan H, Bandi V, Wollenhaupt J (2018) OP0037 Efficacy of tofacitinib after temporary discontinuation in patients with rheumatoid arthritis: analysis of data from open-label long-term extension studies. Ann Rheum Dis 77:69-70. https://doi.org/10.1136/annrheumdis-2018eular.3755
28. Fautrel B (2018) Therapeutic strategy for rheumatoid arthritis patients who have achieved remission. Joint Bone Spine 85:679-685. https://doi.org/10.1016/j.jbspin.2018.02.002

29. Kaine J, Gladstein G, Strusberg I, Robles M, Louw I, Gujrathi S, Pappu R, Delaet I, Pans M, Ludivico C (2012) Evaluation of abatacept administered subcutaneously in adults with active rheumatoid arthritis: impact of withdrawal and reintroduction on immunogenicity, efficacy and safety (phase IIIb ALLOW study). Ann Rheum Dis 71:38-44. https://doi.org/10.1136/annrheumdis-2011-200344

30. US Department of Health and Human Services (2011) Clinical pharmacology and biopharmaceutics review(s). Application Number:2032140rig1s000. https:/www.accessdata.fda.gov/ drugsatfda_docs/nda/2012/203214Orig1s000ClinPharmR.pdf. Accessed 10 Jan 2019

31. Curtis JR, Singh JA (2011) Use of biologics in rheumatoid arthritis: current and emerging paradigms of care. Clin Ther 33:679-707. https://doi.org/10.1016/j.clinthera.2011.05.044

Publisher's note Springer Nature remains neutral with regard to jurisdictional claims in published maps and institutional affiliations. 